\title{
Association of thymosin $\beta 4$ expression with clinicopathological parameters and clinical outcomes of bladder cancer patients
}

\author{
Z. Y. WANG ${ }^{1, \star}$, W. ZHANG ${ }^{2}$, J. J. YANG ${ }^{1}$, D. K. SONG ${ }^{1}$, J. X. WEI ${ }^{1}$, S. GAO ${ }^{3}$
}

${ }^{1}$ Department of Urology, the First Affiliated Hospital, Zhengzhou University, Zhengzhou, Henan Province, China; ${ }^{2}$ Department of Pharmacy, Zhengzhou Orthopaedics Hospital, Zhengzhou, Henan Province, China; ${ }^{3}$ Department of Public Health Administration, The First Affiliated Hospital, Zhengzhou University, Zhengzhou, Henan Province, China

*Correspondence: yuzhi525@163.com

Received April 24, 2016 / Accepted June 16, 2016

\begin{abstract}
The clinical significance of thymosin $\beta 4$ (T $\beta 4$ ) expression in bladder transitional cell carcinoma (BTCC) remains unclear. The present study assessed the relationship between the expression of T $\beta 4$ protein and the clinicopathological features, as well as the prognosis of bladder cancer patients. T $\beta 4$ protein expression in 24 normal bladder and 138 primary BTCC tissue specimens was detected by immunohistochemistry, and the association of this expression with BTCC clinicopathological features and recurrence as well as patient survival was analyzed. T $\beta 4$ expression was significantly stronger in BTCC patients than in normal volunteers. The expression of $\mathrm{T} \beta 4$ was significantly associated with differentiation capability, tumor stage and lymph node metastasis $(P=0.025,0.043$, and 0.039 , respectively). Moreover, $\mathrm{T} \beta 4$ expression was positively correlated with integrin-linked kinase (ILK) and $\beta$-catenin expression $(P=0.042,0.031$, respectively) and inversely correlated with Ecadherin expression $(P=0.022)$. In the present cohort of bladder cancer patients, T $\beta 4$ expression was found to be a predictor of poor survival $(P<0.05)$; however, high T $\beta 4$ expression exhibited unfavorable prognostic value for recurrence. These data suggested that T $\beta 4$ is correlated with the pathogenesis of BTCC. In addition, the patients with higher T $\beta 4$ expression had a shorter survival.
\end{abstract}

Key words: thymosin $\beta 4$, bladder cancer, prognosis, immunohistochemistry, epithelial to mesenchymal transition, integrinlinked kinase, E-cadherin

Bladder transitional cell carcinoma (BTCC) is a prevalent global health problem and is the second most common malignancy of the urinary tract. Approximately $70 \%$ of all newly diagnosed cases present as superficial bladder cancer, the standard treatment for which is a transurethral resection (TUR) of the tumor [1]. However, approximately $60 \%-70 \%$ of these tumors recur, with $25 \%$ of these having progressed to a higher stage or grade [1]. Despite increased understanding of the molecular pathogenesis of bladder cancer, no reliable prognostic markers or risk factors are currently available for predicting the aggressive behavior or recurrence of bladder tumors, especially in in situ carcinoma and early-stage or low-risk tumors.

The epithelial to mesenchymal transition (EMT) is a process by which epithelial cells lose their polarity and convert into a mesenchymal phenotype $[2,3]$. An emerging realization is that the progression of epithelial-derived tumors may also in- volve spatial or temporal occurrences of the EMT, which leads to cellular de-differentiation and loss of adhesive constraints, thereby providing a mechanism for carcinoma cells to acquire a more aggressive phenotype [4]. Furthermore, the EMT positively correlates with poor patient prognosis [5]. A hallmark of the EMT is the loss of E-cadherin expression, which is a very important component of the epithelial phenotype. Reduced E-cadherin expression is often correlated with tumor grade and stage and results in disrupted cell-cell adhesion as well as increased $\beta$-catenin in the nucleus $[6$,$] .$

Thymosin $\beta 4$ (T $\beta 4)$ is a 43 -amino acid peptide that is a member of the beta-thymosin family; T $\beta 4$ has been documented to be involved in a number of processes, including angiogenesis, wound healing, apoptosis, and inflammation $[8,9]$. Recent studies have shown that $\mathrm{T} \beta 4$ is frequently overexpressed in malignant tumors and leads to increased tumor growth, metastasis and the EMT $[10,11]$. Furthermore, the 
presence of $\mathrm{T} \beta 4$ has been reported to facilitate cell migration and prostate cancer progression [12]. T $\beta 4$ expression was shown to be significantly higher in metastasizing tumors than in non-metastasizing tumors and was associated with worse prognosis in early-stage, pulmonary non-small-cell carcinomas [13].

Our previous study [14] demonstrated that the EMT plays a central role in bladder cancer progression and metastasis. In addition, $\mathrm{T} \beta 4$ activity was a dominant factor in triggering the EMT of bladder cancer cells through upregulating ILK (integrin-linked kinase) expression and signal transduction, which led to a high level of $\beta$-catenin and a low level of Ecadherin. However, to date, no clinical data demonstrating the expression patterns of $\mathrm{T} \beta 4$ in bladder transitional cell carcinoma have been available.

In this study, we examined the expression patterns of $\mathrm{T} \beta 4$ in both clinical BTCC cases and normal bladders, and we investigated the relationship between prognostic histopathological characteristics and clinical outcome. Moreover, the same tumor groups were used to evaluate the correlation between the expression of T $\beta 4$ and functionally related proteins, including ILK and $\beta$-catenin.

\section{Patients and methods}

Patients and tissue samples. All patients provided written, informed consent for the use of these clinical materials for research purposes, according to procedures approved by the ethics committee of our hospital. For the immunohistochemical assay, a total of 138 paraffin-embedded BTCC samples and 24 normal bladder tissue specimens (obtained more than $3 \mathrm{~cm}$ away from the tumor border) were collected from the First Affiliated Hospital of Zhengzhou University (Zhengzhou, China) between September, 2011 and December, 2014. All tissue samples were obtained from patients with histologically proven primary urothelial bladder cancer who had undergone TUR-B or partial or radical cystectomy. The clinicopathological data are summarized in Table 1. The patients included 106 males and 32 females, ranging in age from 41 to 88 years (mean age, 62.1 years). The regular follow-ups that were conducted consisted mainly of cystoscopic examination and pelvic computed tomography and were scheduled according to our standard protocol, i.e., every 3 months for at least 2 years, every 6 months for the next 3 years, and then every 12 months for life. Survival time was calculated from the date surgery was performed to the date of death or the date of the last follow-up. The follow-up period was closed on Apr 30,2015 . The mean follow-up period was 29.8 months (range, 5-41 months). The grade and stage of the patients were defined according to the $2004 \mathrm{WHO}$ criteria for grade and the 2009 TNM classification system $[15,16]$.

Immunohistochemistry. T $\beta 4$, ILK, $\beta$-catenin, and $\mathrm{E}$ cadherin expression levels in all paraffin-embedded tumor specimens were detected using an immunohistochemical method. The tissue sections were incubated overnight with monoclonal antibody at a 1:100 dilution and were then treated with a streptavidin-peroxidase immunohistochemical staining kit (Zymed Laboratories Inc., CA, USA), according to the manufacturer's protocol. Samples incubated with normal serum instead of primary antibodies were used as negative controls. Finally, depending on the marker, the different distributions were scored as membranous, cytoplasmic, and/ or nuclear.

Immunohistochemistry scores. Three well-trained and blinded observers examined the slides and scored the T $\beta 4$, ILK, $\beta$-catenin and E-cadherin expression levels. Each slide was evaluated for T $\beta 4$, ILK, $\beta$-catenin and E-cadherin immunoreactivity using a semi-quantitative scoring system for both the intensity of the stain and the percentage of positive neoplastic cells. Stained T $\beta 4$ and ILK deposits in the cytoplasm, $\beta$-catenin deposits in the nucleus and E-cadherin deposits in the membrane were considered positive neoplastic indicators. The intensity of positive staining was scored as follows: 0 (negative), 1 (weak), 2 (moderate), and 3 (strong). The extent of positive staining was scored according to the percentage of positive cells in the respective lesions: $0,0 \% ; 1,1-25 \% ; 2$, $26-50 \% ; 3,51-75 \%$; and $4,>75 \%$. For the purpose of statistical evaluation, tumors with a final staining score of $>3$ were considered to exhibit high expression. The median of this series (i.e., an intensity score of $\geq 2$ with at least $26 \%$ positively stained cells) was used as a threshold for distinguishing tumors with low $(<25 \%)$ or high $(>25 \%)$ levels of T $\beta 4$, ILK, $\beta$-catenin and $\mathrm{E}$-cadherin. These criteria were based on previously published reports $[17,18]$.

Statistical analysis. SPSS, version 13.0 (SPSS Inc., Chicago, IL, USA), was used for all statistical analyses. The relationships between T $\beta 4$ or E-cadherin expression and each clinicopathological parameter were evaluated using a Chi-square test or Fisher's exact test. Patients who died from other diseases were excluded from the survival analysis. Overall survival curves were obtained by the Kaplan-Meier method, and differences between the survival curves were examined using the log-rank test. The Cox proportional hazards model (Cox regression test) was used for multivariate analyses. All reported $P$ values are two-sided, and $P$ values $<0.05$ were considered statistically significant. The correlation between T $\beta 4$ and ILK/ $\beta$-catenin expression was assessed using the Spearman test, and $P<0.05$ was considered statistically significant.

\section{Results}

Expression of T $\beta 4$, ILK, $\beta$-catenin and E-cadherin in BTCC tissue samples. Immunohistochemistry was used to investigate $\mathrm{T} \beta 4$ protein expression in 24 normal bladder tissue specimens and 138 paraffin-embedded BTCC tissue samples that represented different stages of bladder cancer. As shown in Figure 1, positive T $\beta 4$ immunostaining was predominantly observed in the cytoplasm of carcinoma cells at significantly higher levels than those in normal cells; however, E-cadherin staining was mainly observed in the membranes of normal 
Table 1. Correlation between T $\beta 4 / E$-cadherin expression and clinicopathological characteristics of bladder cancer patients

\begin{tabular}{|c|c|c|c|c|c|c|c|}
\hline \multirow{2}{*}{ Variable } & \multirow{2}{*}{ Total } & \multicolumn{2}{|c|}{$\mathrm{T} \beta 4$} & \multirow{2}{*}{$P$-value } & \multicolumn{2}{|c|}{ E-cadherin } & \multirow{2}{*}{$P$-value } \\
\hline & & Low expression ${ }^{\mathrm{a}}$ & High expression $^{\mathrm{b}}$ & & Low expression ${ }^{\mathrm{a}}$ & High expression $^{\mathrm{b}}$ & \\
\hline All cases & 162 & & & & & & \\
\hline Normal & 24 & 20 & 4 & & 1 & 23 & \\
\hline BTCC & 138 & 41 & 97 & $0.027^{\star}$ & 106 & 32 & $0.018^{*}$ \\
\hline \multicolumn{8}{|l|}{ Age (years) } \\
\hline$\leq 60$ & 59 & 19 & 40 & & 43 & 16 & \\
\hline$>60$ & 79 & 22 & 57 & 0.584 & 63 & 16 & 0.344 \\
\hline \multicolumn{8}{|l|}{ Gender } \\
\hline Male & 106 & 32 & 74 & & 77 & 29 & \\
\hline Female & 32 & 9 & 23 & 0.821 & 29 & 3 & 0.055 \\
\hline \multicolumn{8}{|c|}{ Tumor size $(\mathrm{cm})$} \\
\hline$\leq 3$ & 90 & 25 & 65 & & 61 & 29 & \\
\hline$>3$ & 48 & 16 & 32 & 0.505 & 45 & 3 & 0.078 \\
\hline \multicolumn{8}{|c|}{ Number of tumors } \\
\hline Unifocal & 51 & 19 & 32 & & 39 & 12 & \\
\hline Multifocal & 87 & 22 & 65 & 0.058 & 67 & 20 & 0.940 \\
\hline \multicolumn{8}{|l|}{ T stage } \\
\hline Tis & 9 & 2 & 7 & & 6 & 3 & \\
\hline $\mathrm{Ta} / / \mathrm{T} 1$ & 61 & 30 & 31 & & 50 & 11 & \\
\hline $\mathrm{T} 2 / \mathrm{T} 3 / \mathrm{T} 4$ & 68 & 9 & 59 & $0.043^{*}$ & 51 & 17 & 0.625 \\
\hline \multicolumn{8}{|l|}{ Grade } \\
\hline G1 & 36 & 28 & 8 & & 12 & 24 & \\
\hline G2-G3 & 102 & 13 & 89 & $0.025^{*}$ & 94 & 8 & $0.023^{*}$ \\
\hline \multicolumn{8}{|c|}{ Lymph node metastasis } \\
\hline N0 & 78 & 26 & 52 & & 56 & 22 & \\
\hline $\mathrm{N} 1 / \mathrm{N} 2 / \mathrm{N} 3$ & 60 & 15 & 45 & $0.039^{*}$ & 50 & 10 & 0.113 \\
\hline
\end{tabular}

${ }^{a}$ Low expression: staining score $<3$; ${ }^{b}$ High expression: staining score $\geq 3$; ${ }^{*} P<0.05$

epithelial cells. Positive staining for ILK and $\beta$-catenin was partially observed in not only the cytoplasm and nuclei of tumor cells but also in intraglandular deposits within cancerous lesions (Figure 1).

Correlation between T $\beta 4 / E$-cadherin protein expression and clinicopathological features. In the current study, 34 patients $(24.6 \%)$ had a poorly differentiated BTCC, 68 patients $(49.3 \%)$ had moderately differentiated BTCC, and 36 patients $(26.1 \%)$ had well differentiated BTCC. The association between $\mathrm{T} \beta 4 / \mathrm{E}$-cadherin protein expression and the clinicopathological features of BTCC was examined. As shown in Table 1, high levels of $\mathrm{T} \beta 4$ protein expression were significantly correlated with tumor grade and stage, as well as lymph node metastasis $(P=0.025,0.043$, and 0.039 , respectively). However, $\mathrm{T} \beta 4$ protein expression was not associated with other clinicopathological features, such as age, sex, tumor size, and number of tumors. In contrast, E-cadherin protein expression was not only found significantly more often in the normal group than in the BTCC group $(P=0.018)$ but also was significantly correlated with tumor grade $(P=0.023)$.

High ILK, high $\beta$-catenin and low E-cadherin expression levels are associated with high $\mathrm{T} \beta 4$ expression in patients with advanced-stage BTCC. T $\beta 4$ expression was significantly positively correlated with ILK and $\beta$-catenin expression $(P=$ $0.042,0.031$, respectively), and E-cadherin expression was lower in the high-level T $\beta 4$ BTCC tissues than in the low-

Table 2. Relationship between T $\beta 4$ and ILK/ $\beta$-catenin expression

\begin{tabular}{lccc}
\hline \multirow{2}{*}{ Variables } & \multicolumn{2}{c}{$\mathrm{T} \beta 4$} & \\
\cline { 2 - 3 } & $\begin{array}{c}\text { Low expres- } \\
\text { sion }^{\mathrm{a}}(\%)\end{array}$ & $\begin{array}{c}\text { High expression } \\
\text { ( }\end{array}$ & P-value \\
\hline ILK & & & \\
$\quad$ Low expression (\%) & $31 / 41(75.61)$ & $28 / 97(28.87)$ & \\
High expression (\%) & $10 / 41(24.39)$ & $69 / 97(71.13)$ & $0.042^{*}$ \\
$\beta$-catenin & & & \\
Low expression (\%) & $26 / 41(63.41)$ & $32 / 97(32.99)$ & \\
High expression (\%) & $15 / 41(36.59)$ & $65 / 97(67.01)$ & $0.031^{*}$ \\
E-cadherin & & & \\
Low expression (\%) & $16 / 41(39.02)$ & $90 / 97(92.78)$ & \\
High expression (\%) & $25 / 41(60.98)$ & $7 / 97(7.22)$ & $0.022^{*}$ \\
\hline
\end{tabular}

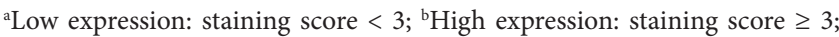
${ }^{\star} P<0.05$ 


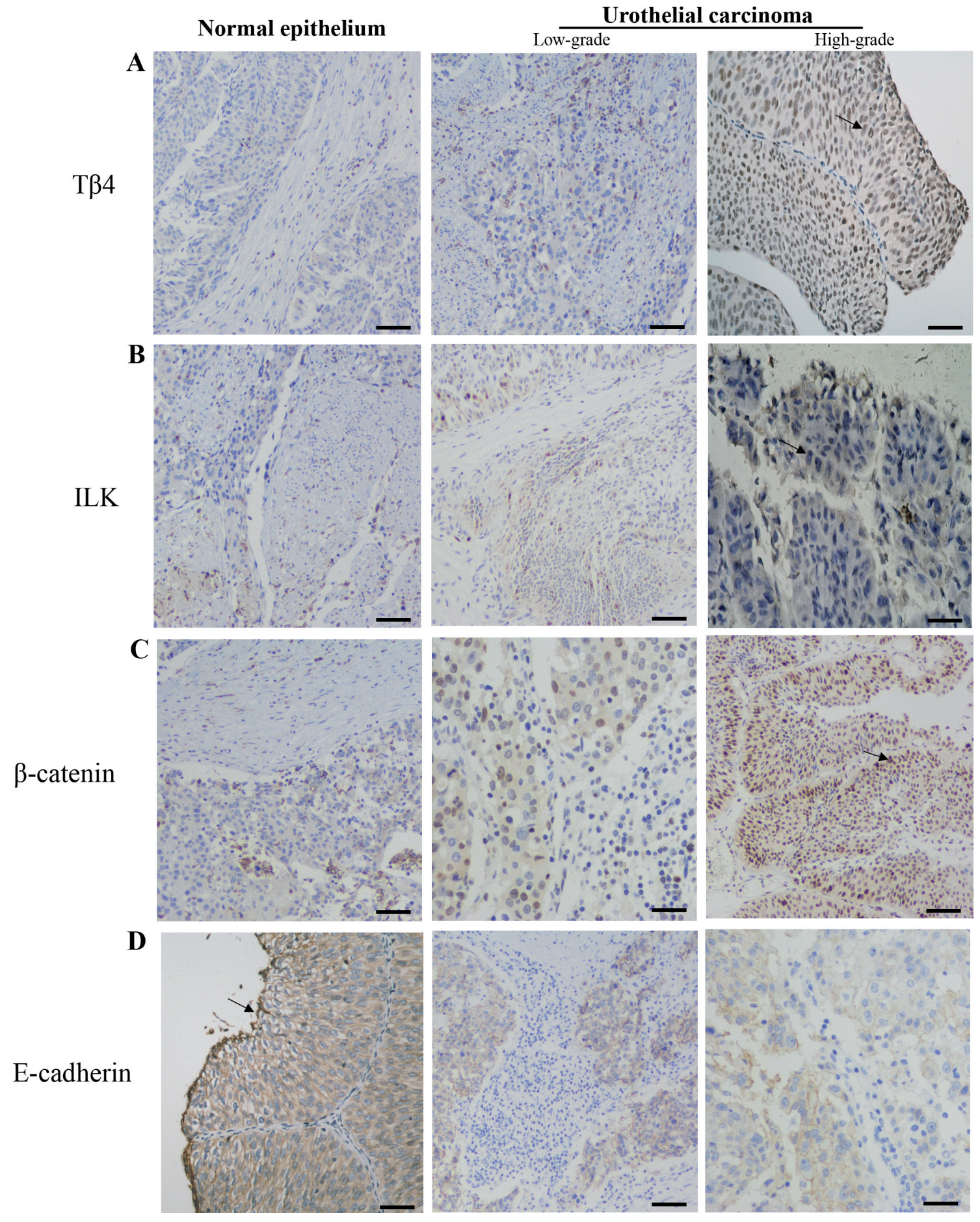

Figure 1. Immunohistochemical staining of EMT markers. (A), Positive cytoplasmic T $\beta 4$ expression in high-grade BTCC tissue samples (arrow). (B) Positive cytoplasmic ILK expression in high-grade BTCC tissue samples (arrow). (C) Positive nuclear $\beta$-catenin staining in high-grade BTCC tissue samples (arrow). (D) Positive membranous E-cadherin expression in normal bladder urothelium (arrow). Bars represent $50 \mu \mathrm{m}$.

level T $\beta 4$ BTCC tissues $(P=0.022)$ (Table 2). Interestingly, we found these strongly positive correlations between $\mathrm{T} \beta 4$ and ILK/ $\beta$-catenin expression levels more often in highly invasive tumors; however, no significant correlations were observed between the expression levels of each protein in less-invasive tumors (data not shown).

Impact of $T \beta 4$ protein expression on the prognosis of BTCC patients. The Kaplan-Meier and log-rank tests that 

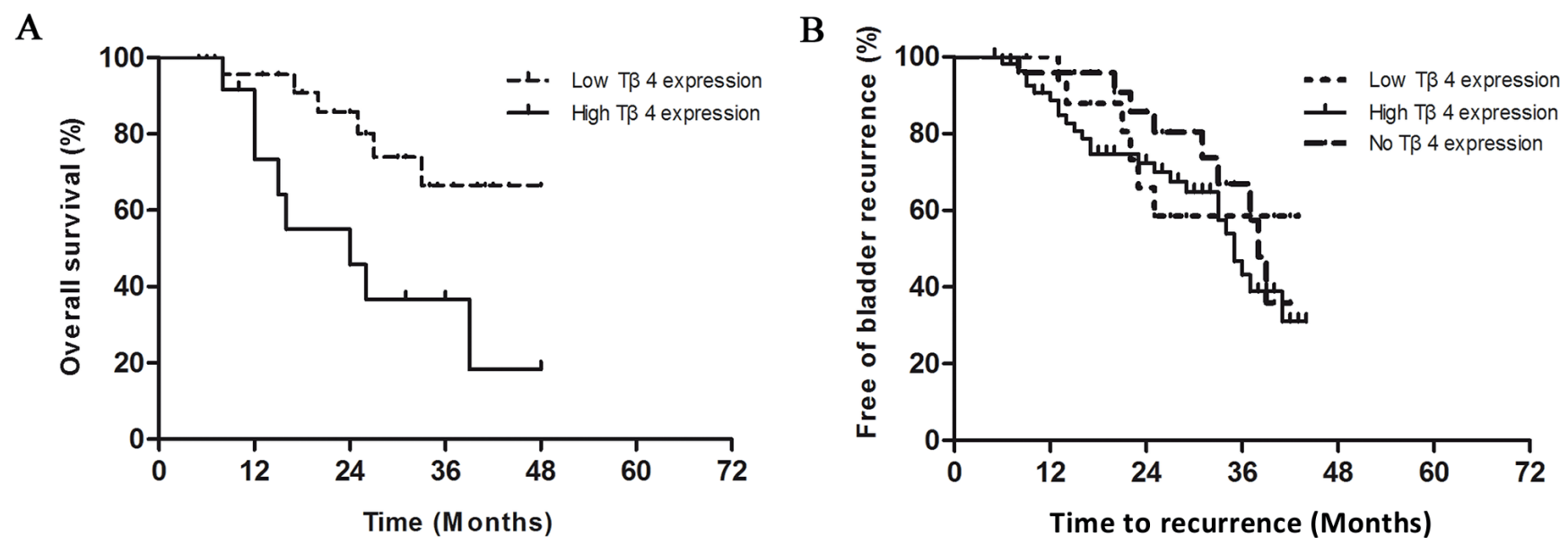

Figure 2. Kaplan-Meier analysis of overall survival (A) and recurrence-free survival (B) in all bladder cancer patients according to T $\beta 4$ expression.

were used for univariate analyses revealed statistically significant differences in the overall survival of BTCC patients who did and did not have high T $\beta 4$ expression $(P=0.035)$ (Figure 2A). The log-rank test further demonstrated that advanced pathological stage and lymph node metastasis were closely correlated with shorter survival $(P=0.015,0.038$, respectively) (Table 3 ). In addition, a multivariate analysis using the Cox proportional hazard regression model revealed T $\beta 4$ level, pathological stage and lymph node metastasis as independent prognostic factors of overall survival (Table 4). As other EMT biomarkers had no influence on survival in the univariate tests, we did not perform further multivariate Cox-regression analyses.
The total of $52(37.68 \%)$ patients experienced recurrence during the observation period: one recurrence was observed in $35(25.36 \%)$ patients; two recurrences were observed in 10 (7.25\%) patients; and three or more recurrences were observed in 7 (5.07\%) patients. The univariate and multivariate analyses of recurrence risks showed that the number of tumors, the degree of tumor invasion and tumor grade are the independent prognostic factors that affected recurrence in the BTCC patients (Table 3, Table 4). Although T $\beta 4$ expression was not a significant prognostic factor for BTCC recurrence, high T $\beta 4$ staining intensity was observed more often in tumors from patients with than without recurrence/metastasis, as shown in Figure 2B.

Table 3. Univariate analysis of risk factors for overall survival and recurrence in patients with BTCC

\begin{tabular}{|c|c|c|c|c|c|c|}
\hline \multirow{2}{*}{ Variable } & \multicolumn{3}{|c|}{ Survival } & \multicolumn{3}{|c|}{ Recurrence } \\
\hline & HR & $95 \% \mathrm{CI}$ & $P$-value & HR & $95 \% \mathrm{CI}$ & $P$-value \\
\hline \multicolumn{7}{|l|}{ Age (years) } \\
\hline$\leq 60$ versus $>60$ & 1.312 & $0.921-1.862$ & 0.141 & 0.961 & $0.511-1.827$ & 0.902 \\
\hline \multicolumn{7}{|l|}{ Gender } \\
\hline Male versus Female & 1.043 & $0.705-1.557$ & 0.852 & 1.393 & $0.792-2.472$ & 0.264 \\
\hline \multicolumn{7}{|l|}{ Tumor size $(\mathrm{cm})$} \\
\hline$\leq 3$ versus $>3$ & 1.063 & $0.741-1.529$ & 0.753 & 0.945 & $0.496-1.823$ & 0.922 \\
\hline \multicolumn{7}{|l|}{ Number of tumors } \\
\hline Unifocal versus Multifocal & 1.094 & $0.772-1.567$ & 0.625 & 3.013 & $2.725-3.362$ & 0.024 \\
\hline \multicolumn{7}{|l|}{ T stage } \\
\hline $\mathrm{Ta} / \mathrm{Tis} / \mathrm{T} 1$ versus $\mathrm{T} 2 / \mathrm{T} 3 / \mathrm{T} 4$ & 4.864 & $2.833-5.644$ & 0.015 & 4.684 & $3.656-5.163$ & 0.013 \\
\hline \multicolumn{7}{|l|}{ Lymph node metastasis } \\
\hline N0 versus N1/N2/N3 & 3.325 & $2.863-4.037$ & 0.038 & 1.476 & $1.053-1.954$ & 0.137 \\
\hline \multicolumn{7}{|l|}{ Grade } \\
\hline $\mathrm{G} 1$ versus $\mathrm{G} 2$ and $\mathrm{G} 3$ & 0.947 & $0.641-1.398$ & 0.916 & 2.657 & $2.365-3.186$ & 0.041 \\
\hline \multicolumn{7}{|l|}{$\mathrm{T} \beta 4$ expression } \\
\hline Low versus high & 3.751 & $3.045-4.352$ & 0.035 & 1.281 & $0.992-1.488$ & 0.454 \\
\hline
\end{tabular}

HR, hazard risk; 95\% CI, 95\% confidence interval 
Table 4. Multivariate analysis of prognostic factors for overall survival and recurrence in patients with BTCC

\begin{tabular}{|c|c|c|c|c|c|c|}
\hline \multirow{2}{*}{ Variable } & \multicolumn{3}{|c|}{ Survival } & \multicolumn{3}{|c|}{ Recurrence } \\
\hline & HR & $95 \%$ CI & $P$-value & HR & $95 \% \mathrm{CI}$ & $P$-value \\
\hline \multicolumn{7}{|l|}{ Number of tumors } \\
\hline Unifocal versus Multifocal & & & & 2.883 & $2.705-3.596$ & 0.033 \\
\hline \multicolumn{7}{|l|}{ T stage } \\
\hline $\mathrm{Ta} / \mathrm{Tis} / \mathrm{T} 1$ versus $\mathrm{T} 2 / \mathrm{T} 3 / \mathrm{T} 4$ & 3.784 & $2.806-4.112$ & 0.029 & 4.484 & $3.556-4.963$ & 0.019 \\
\hline \multicolumn{7}{|l|}{ Lymph node metastasis } \\
\hline N0 versus N1/N2/N3 & 2.815 & $2.603-3.154$ & 0.047 & & & \\
\hline \multicolumn{7}{|l|}{ Grade } \\
\hline $\mathrm{G} 1$ versus $\mathrm{G} 2$ and $\mathrm{G} 3$ & & & & 2.515 & $2.235-2.986$ & 0.044 \\
\hline \multicolumn{7}{|l|}{$\mathrm{T} \beta 4$ expression } \\
\hline Low versus high & 3.022 & $2.901-3.327$ & 0.034 & & & \\
\hline
\end{tabular}

HR, hazard risk; 95\% CI, 95\% confidence interval

\section{Discussion}

Recurrence and distant metastasis are frequently observed in BTCC patients, and the 5-year survival rate for high-grade tumors remains quite low. Therefore, discovering novel molecular targets that may be used in the development of more effective therapies for BTCC patients is crucial.

Numerous in vitro and in vivo studies have suggested that the EMT is associated with cancer cell invasion and metastasis in various malignancies, including BTCC. In this study, we first examined the relationship between $\mathrm{T} \beta 4$ and $\mathrm{E}$-cadherin expression and the clinicopathological features of BTCC. Our findings revealed that the expression rate of T $\beta 4$ in BTCC and normal bladder tissue was $70.3 \%$ and $16.7 \%$, respectively. High T $\beta 4$ expression was found in BTCC tissue, supporting our previous finding of high T $\beta 4$ mRNA expression in BTCC tissue. Furthermore, there was a trend of increasing $\mathrm{T} \beta 4$ expression with both increasing tumor grade and stage. Though high T $\beta 4$ expression was not observed more often in non-muscle-invasive bladder urothelial carcinomas (Ta/Tis/ $\mathrm{T} 1$ ), our results revealed a slightly increase in the expression of $\mathrm{T} \beta 4$ in the patients with stage Tis (7/9). This finding is possibly due to the fact that urothelial CIS is always high-grade, which is strongly associated with aggressive bladder cancer behavior, and high $\mathrm{T} \beta 4$ expression in carcinoma in situ favours tumour growth and invasion. Moreover, increased T $\beta 4$ expression has also been correlated with lymph node metastasis. Our data show a statistically significant association between T $\beta 4$ overexpression and poor prognostic histopathological features, as well as clinical BTCC aggressiveness. In contrast with T $\beta 4$, E-cadherin expression was decreased in BTCC tissue. In addition, while E-cadherin expression was associated with the degree of BTCC tissue differentiation $(P=0.023)$, it was not associated with other clinical pathological features $(P>0.05)$. More importantly, while T $\beta 4$ expression was detected with lower sensitivity in low-grade tumors, it was reliably detected in high-grade tumors, with a sensitivity of up to $100 \%$ (data not shown). These results indicate that under the circumstances of this study, $\mathrm{T} \beta 4$ had limited potential as a marker for the early detection of urothelial cancer.

$\mathrm{T} \beta 4$ may provide a mechanism for carcinoma cells to acquire a more aggressive phenotype through inducing the EMT by activating ILK and $\beta$-catenin, as well as abolishing E-cadherin function [11]. This study also examined the expression patterns of $\mathrm{T} \beta 4$ and other proteins involved in the EMT in BTCC tissue, including ILK and $\beta$-catenin. The expression of T $\beta 4$, ILK and $\beta$-catenin were weak during the early stages (Ta to T1) of BTCC but were significantly increased from stage T2 onward. The immunohistochemistry results demonstrated that ILK/ $\beta$-catenin expression was significantly higher in samples with high rather than low $\mathrm{T} \beta 4$ expression; in addition, a positive correlation was found between T $\beta 4$, ILK and $\beta$-catenin expression in the BTCC samples. Furthermore, high T $\beta 4$ expression was detected in 90 of 97 cases with low E-cadherin expression in tumor tissues, and Spearman's analysis revealed that E-cadherin expression was negatively correlated with $\mathrm{T} \beta 4$ expression in BTCC tissues $(P=0.022)$, as shown in Table 2. Consistent with the results of previous studies, these findings suggest that $\mathrm{T} \beta 4$ can play an important role in BTCC aggressiveness through factors such as ILK and $\beta$-catenin and may trigger early-stage tumor invasion and metastasis.

The multivariate analyses indicated that TNM stage and lymph node status were exclusively independent prognostic factors for BTCC patients with high T $\beta 4$ expression, which was in accordance with a previous observation that TNM stage and lymph node status were the most common prognostic factors of malignant tumors. ${ }^{16}$ Moreover, positive T $\beta 4$ staining was consistently found in locally invasive, high-grade BTCC, and patients with higher $\mathrm{T} \beta 4$ expression survived for a shorter time. These results may be partially explained by the EMT being an event that takes place early in tumor progression [19]. Furthermore, once tumor cells infiltrate a distant organ, they undergo a reverse EMT transition and regain their epithelial phenotype along with increased self-renewal and proliferative capacity [20]. Therefore, although the EMT markers tested 
in this study failed to predict long-term outcomes in our carcinoma cohort, they may be valuable indicators of locally invasive cancer.

Past studies of bladder cancer have demonstrated that the EMT is closely associated with grave clinical characteristics, such as recurrence and poorer survival [21]. However, after 5-41 months of active surveillance, data revealed that there were no significant differences in $\mathrm{T} \beta 4$ expression between recurring and non-recurring tumors $(P=0.454)$ (Table 3$)$. Probable explanations for this observation include the following: [1] In our study, while lower $\mathrm{T} \beta 4$ expression was observed in 70 patients with Ta/Tis/T1 tumors compared with that found in patients with stage T2/T3/T4 tumors $(P<0.05)$, in many cases, non-muscle-invasive bladder cancer has high recurrence due to low progression rates and long-term survival; in addition, patients with muscle-invasive bladder cancer are at higher risk for cancer-specific mortality [22]. The degree of invasion and number of tumors are the most important prognostic factors for the recurrence of non-muscle-invasive bladder cancer [23]. Nevertheless, in this study, there was no significant association between $\mathrm{T} \beta 4$ and the number of tumors. One potential mechanism underlying this observation is that high T $\beta 4$ expression mainly accelerates the deteriorative process via specific EMTinducing signals in advanced BTCC, thereby inducing local invasion and distant metastasis; however, the precise details of how this process directly affects recurrence in early-stage carcinoma remains unknown. In addition, E-cadherin is not only the first and most important regulator of the EMT but also is clearly associated with the clinical outcomes of BTCC, such as recurrence [24]. However, several factors (e.g., microRNA-205, Twist) or pathways (e.g., epidermal growth factor receptor, tumor necrosis factor-related apoptosisinducing ligand) might interact with $\mathrm{T} \beta 4$ or influence the biological features of BTCC through acting on E-cadherin expression [25]; as a result, our findings demonstrated that $\mathrm{T} \beta 4$ was likely not an independent prognostic factor for recurrence.

Routine lymphadenectomy was also performed in patients who underwent radical cystectomy, and the results of both univariate and multivariate analyses demonstrated that lymphatic metastasis positively impacted overall survival.

In conclusion, our study clarified the correlation between $\mathrm{T} \beta 4$ expression and clinicopathological parameters of BTCC, as well as the prognostic value of $\mathrm{T} \beta 4$ protein expression in advanced BTCC. Although our results are promising, our study has several limitations. Further functional analyses using well-defined models and more elaborate approaches will not only improve our understanding of T $\beta 4$ but also contribute to the development of novel diagnostic and therapeutic strategies against bladder cancer.

Acknowledgments: This study was supported by National Science Council (Grants No. 81100464), aim for the Top University Plan, of the Republic of China.

\section{References}

1] KAUFMAN DS, SHIPLEY WU, FELDMAN AS. Bladder cancer. Lancet 2009; 374: 239-249. http://dx.doi.org/10.1016/ $\underline{\text { S0140-6736(09)60491-8 }}$

[2] THIERY JP. Epithelial-mesenchymal transitions in development and pathologies. Curr Opin Cell Biol 2003; 15: 740-746. http://dx.doi.org/10.1016/j.ceb.2003.10.006

[3] THIERY JP, SLEEMAN JP. Complex networks orchestrate epithelial-mesenchymal transitions. Nat Rev Mol Cell Biol 2006; 7: 131-142. http://dx.doi.org/10.1038/nrm1835

[4] THIERY, JP. Epithelial-mesenchymal transitions in tumour progression. Nat. Rev. Cancer 2002; 2: 442-454. http://dx.doi. org/10.1038/nrc822

[5] HUGO H, ACKLAND ML, BLICK T, LAWRENCE MG, CLEMENTS JA, WILLIAMS ED et al. Epithelial-mesenchymal and mesenchymal-epithelial transitions in carcinoma progression. J Cell Physiol 2007; 213: 374-383. http://dx.doi.org/10.1002/ jcp. 21223

[6] COWIN P, ROWLANDS TM, HATSELL SJ. Cadherins and catenins in breast cancer. Curr Opin Cell Biol 2005; 17: 499-508. http://dx.doi.org/10.1016/j.ceb.2005.08.014

[7] JUNGHANS D, HAAS IG, KEMLER R. Mammalian cadherins and protocadherins: about cell death, synapses and processing. Curr Opin Cell Biol 2005; 17: 446-452. http://dx.doi. org/10.1016/j.ceb.2005.08.008

[8] PHILP D, ST-SURIN S, CHA HJ, MOON HS, KLEINMAN HK, ELKIN M. Thymosin beta 4 induces hair growth via stem cell migration and differentiation. Ann N Y Acad Sci 2007; 1112: 95-103. http://dx.doi.org/10.1196/annals.1415.009

[9] PHILP D, GOLDSTEIN AL, KLEINMAN HK. Thymosin beta4 promotes angiogenesis, wound healing, and hair follicle development. Mech Ageing Dev 2004; 125: 113-115. http:// dx.doi.org/10.1016/j.mad.2003.11.005

[10] WANG WS, CHEN PM, HSIAO HL, WANG HS, LIANG WY, SU Y. Overexpression of the thymosin beta-4 gene is associated with increased invasion of SW480 colon carcinoma cells and the distant metastasis of human colorectal carcinoma. Oncogene 2004; 23: 6666-6671. http://dx.doi.org/10.1038/ sj.onc. 1207888

[11] HUANG HC, HU CH, TANG MC, WANG WS, CHEN PM, SU Y. Thymosin beta4 triggers an epithelial-mesenchymal transition in colorectal carcinoma by upregulating integrinlinked kinase. Oncogene 2007; 26: 2781-2790. http://dx.doi. org/10.1038/sj.onc. 1210078

[12] ITO M, IGUCHI K, USUI S, HIRANO K. Overexpression of thymosin beta4 increases pseudopodia formation in LNCaP prostate cancer cells. Biol Pharm Bull 2009; 32: 1101-1104. http://dx.doi.org/10.1248/bpb.32.1101

[13] JI P, DIEDERICHS S, WANG W, BOING S, METZGER R, SCHNEIDER PM et al. MALAT-1, a novel noncoding RNA, and thymosin beta4 predict metastasis and survival in early-stage non-small cell lung cancer. Oncogene 2003; 22: 8031-8041. http://dx.doi.org/10.1038/sj.onc.1206928

[14] WANG ZY, ZENG FQ, ZHU ZH, JIANG GS, LV L, WAN F et al. Evaluation of thymosin $\beta 4$ in the regulation of epithelial-mesenchymal transformation in urothelial carcinoma. 
Urol Oncol 2012; 30: 167-176. http://dx.doi.org/10.1016/j. urolonc.2010.02.009

[15] SAUTER G, ALGABA F, AMIN M, BUSCH C, CHEVILLE J, GASSER T et al. Tumor of urinary system: non-invasive urothelial neoplasia. p 110. In: Eble JN, Sauter G, Epstein JI, Sesterhenn IA editors. Pathology and genetics of tumours of the urinary system and male genital organs. Lyon IARCC Press 2004 ISBN 92-832-2412-4.

[16] SOBIN LH, GOSPODARIWICZ M, WITTEKIND C, editors. TNM classification of malignant tumors. UICC International Union against cancer. 7th ed. Chichester Wiley-Blackwell 2009 ISBN 978-1-4443-3241-4, p 336.

[17] KWON HC, ROH MS, OH SY, KIM SH, KIM MC, KIM JS et al. Prognostic value of expression of ERCC1, thymidylate synthase, and glutathione S-transferase P1 for 5-fluorouracil/ oxaliplatin chemotherapy in advanced gastric cancer. Ann Oncol 2007; 18: 504-509. http://dx.doi.org/10.1093/annonc/ $\underline{\operatorname{mdl} 430}$

[18] ISHIGAMI S, UENO S, ARIGAMI T, UCHIKADO Y, SETOYAMA T, ARIMA H et al. Prognostic impact of CD133 expression in gastric carcinoma. Anticancer Res 2010; 30: 2453-2457.

[19] CHEN J, HAN Q, PEI D. EMT and MET as paradigms for cell fate switching. J Mol Cell Biol 2012; 4: 66-69. http://dx.doi. org/10.1093/jmcb/mjr045

[20] DE WEVER O, PAUWELS P, DE CRAENE B, SABBAH M, EMAMI S, REDEUILH G ET AL. Molecular and pathological signatures of epithelial-mesenchymal transitions at the cancer invasion front. Histochem Cell Biol 2008; 130: 481-494. http:// dx.doi.org/10.1007/s00418-008-0464-1

[21] PALIWAL P, ARORA D, MISHRA AK. Epithelial mesenchymal transition in urothelial carcinoma: twist in the tale. Indian J Pathol Microbiol 2012; 55: 443-449. http://dx.doi. org/10.4103/0377-4929.107777

[22] BURGER M, CATTO JWF, DALBAGNI G, GROSSMAN HB, HERR H, KARAKIEWICZ $P$ et al. Epidemiology and risk factors of urothelial bladder cancer. Eur Urol 2013; 63: 234-241. http://dx.doi.org/10.1016/j.eururo.2012.07.033

[23] SYLVESTER RJ, VAN DER MEIJDEN AP, OOSTERLINCK W, WITJES JA, BOUFFIOUX C, DENIS L et al. Predicting recurrence and progression in individual patients with stage Ta T1 bladder cancer using EORTC risk tables: a combined analysis of 2596 patients from seven EORTC trials. Eur Urol 2006; 49: 466-475; discussion 475. http://dx.doi.org/10.1016/j. eururo.2005.12.031

[24] BLACK PC, BROWN GA, INAMOTO T, SHRADER M, ARORA A, SIEFKER-RADTKE AO et al. Sensitivity to epidermal growth factor receptor inhibitor requires E-cadherin expression in urothelial carcinoma cells. Clin Cancer Res 2008; 14: 1478-1486. http://dx.doi.org/10.1158/1078-0432. CCR-07-1593

[25] SOSNE G, QIU P, GOLDSTEIN AL, WHEATER M. Biological activities of thymosin beta4 defined by active sites in short peptide sequences. FASEB J 2010; 24: 2144-2151. http:// dx.doi.org/10.1096/f.09-142307 